\title{
An E-box-containing region is involved in the tissue-specific expression of the human MC2R gene
}

\author{
A Blondet, M Doghman, P Durand, M Bégeot and D Naville \\ INSERM U418-INRA UMR 1245 and IFR 62, Hôpital Debrousse and Claude Bernard University, Lyon, France \\ (Requests for offprints should be addressed to D Naville, Hôpital Debrousse, 29, rue Soeur Bouvier, 69322 Lyon Cedex 05, France; Email: \\ naville@lyon.inserm.fr)
}

\begin{abstract}
Expression of the melanocortin receptor $(M C 2 R)$ gene is limited to adrenocortical cells and the aim of this study was to determine the factors responsible for this tissue specificity. We used different fragments of the human (h) MC2R gene promoter, inserted in a vector upstream of the luciferase reporter gene, to transiently transfect either bovine adrenocortical (BAC) cells or granulosa cells from bovine ovaries (B-Gran). Similar promoter activities were obtained in both cell types using constructs containing fragments up to $1017 \mathrm{bp}$ of the $h M C 2 R$ gene promoter. On the contrary, a 2-fold decrease was obtained after transfection of the B-Gran cells with vectors containing $1069 \mathrm{bp}$ and more of the promoter. Results obtained here using BAC cells confirmed our previous data on human cells showing that steroidogenic factor 1 is the major transactivating factor involved in the basal expression of the $h M C 2 R$ gene in adrenal cells. However, we showed that this factor did not permit, by itself, the expression of the $h M C 2 R$ gene in B-Gran cells despite its expression in these cells. This study demonstrated for the first time that an E-box (located at $-1020 \mathrm{bp}$ ) is involved in the repression of $h M C 2 R$ gene expression in granulosa cells through interactions with several factors, such as activator protein 4 , as suggested by electrophoretic mobility shift assay analyses.
\end{abstract}

Journal of Molecular Endocrinology (2004) 32, 811-823

\section{Introduction}

The adrenocorticotrophin $(\mathrm{ACTH})$ receptor or melanocortin receptor type 2 (hMC2R) represents a good example of a cell-specifically regulated gene as it is expressed almost exclusively in the adrenocortical gland. There is one report of the presence of MC2R mRNA in human skin, using RT-PGR, but no evidence of the presence of the receptor itself (Slominski et al. 1996). In the mouse the $M C 2 R$ gene is also expressed in adipose tissue. This has been shown by demonstrating the presence of binding sites for labelled ACTH (Grunfeld et al. 1985) and by RT-PCR and Northern analysis (Boston \& Cone 1996). But levels of expression are limited in this tissue when compared with the levels present in mouse adrenal tissue. On the contrary, there is no evidence of the presence of $\mathrm{MC} 2 \mathrm{R}$ in human adipocytes as its mRNA cannot be detected by RT-PCR (Cammas $\&$ Clark 1995). The question which must be considered is the nature of the cis-regulatory elements and nuclear factors that control this adrenal expression of the $M C 2 R$ gene.

In primary cultured human adrenal fasciculatareticularis cells, hMC2R is positively regulated by both ACTH and angiotensin-II, showing an increase in ACTH receptor number and mRNA accumulation (Lebrethon et al. 1994). Among the transcription factors necessary for the expression of the human $M C 2 R$ gene are the steroidogenic factor 1 (SF-1) which is involved both in constitutive and cAMP-controlled expression (Marchal et al. 1998, Naville et al. 1999) and activator protein (AP-1) which is involved in angiotensin II-stimulated expression (Naville et al. 2001). SF-1 also acts as a positive factor on mouse $M C 2 R$ gene expression (Cammas et al. 1997). It has been postulated that SF-1 could play a role in the cell-specific expression of the $h M C 2 R$ gene but, as it is present in all steroidogenic cells, it cannot be the only factor involved and could possibly act by co-operation 
with other factors. At this time, there is no record of such factors which could mediate the tissuespecific expression of the $h M C 2 R$ gene.

The aim of this study was to map other regulatory elements which could be involved in the cell-specific expression of the $h M C 2 R$ gene. These might be binding sites for factors either permitting efficient expression of the $h M C 2 R$ gene in adrenal cells and/or inhibiting its expression in all other tissues. For this purpose, we used two different types of cells which both express SF-1: bovine adrenocortical and granulosa cells in primary culture, the latter ones showing no expression of the $M C 2 R$ gene. We have demonstrated here the presence of one region which is partially responsible for the cell-specific expression of $h M C 2 R$. This region contains an E-box which binds factor(s) with inhibitory functions in granulosa cells.

\section{Materials and methods}

\section{Materials}

Penicillin, streptomycin, nystatin, fetal calf serum (FCS), trypsin, ITS (10 mg/l insulin, $5.5 \mathrm{mg} / \mathrm{l}$ transferrin and $5 \mu \mathrm{g} / 1$ selenium), Dulbecco's modified Eagle's medium/Ham's nutrient mixture F-12 (DMEM/F-12; 15 mM HEPES), McCoy's 5A medium and restriction enzymes were purchased from Invitrogen (Cergy-Pontoise, France). Oligonucleotides were prepared by Sigma-Genosys (Cambridge, Cambs, UK).

\section{Cell culture}

Primary cultures of bovine adrenal fasciculatareticularis adrenal (BAG) cells were prepared by sequential treatment of adrenal cortical slices with trypsin $(0 \cdot 15 \%)$ as previously described (Derrien et al. 1996). The cells were cultured in a chemically defined medium (DMEM/F-12) supplemented with $1 \%$ ITS and vitamin $\mathrm{C}\left(10^{-4} \mathrm{M}\right)$.

Primary cultures of bovine granulosa (B-Gran) cells were prepared from ovaries after the collection of large follicles (Lauber et al. 1993). Briefly, the follicular fluid was aspirated and granulosa cells were scraped out using a plastic loop. The cells were cultured in McCoy's 5A medium supplemented with $1 \%$ ITS and $2 \cdot 5 \%$ FCS.

The HEK293 (human embryonic kidney) cell line was cultured in DMEM/F-12 supplemented with $7 \cdot 5 \%$ FCS.
Table 1 Sequences of the sense strand of the oligonucleotides used for gel shift experiments and directed mutagenesis. All sequences are written $5^{\prime}$ to $3^{\prime}$. The E-box element is in bold

\section{Sequence}

Inr mut $\quad$ ctctccgagetggttccttctcattc

Spe gtggaacgccgggttcagctgcagggcatgtt

$\mathrm{SpE}$ mut Eb gaacgccgggtttagttctcagggcatgttgc

SpE mut Oc $\quad$ gtggaacgccgggttcagctgcagggctaagt AP4sv gcggaaagaaccagctgtggaatgtgtgtcagt

mut, mutation; Inr, initiator element; mut Oc, mutation in a putative octamer-binding site. mut Eb, mutation in the E-box.

All complete media contained penicillin $(100 \mathrm{U} / \mathrm{ml})$, streptomycin $(0 \cdot 1 \mathrm{mg} / \mathrm{ml})$ and nystatin $(20 \mathrm{U} / \mathrm{ml})$.

\section{Reporter vector constructions}

All constructs were obtained in pGL3 basic which contains the firefly luciferase reporter gene (Promega, Charbonniè res, France) as previously described (Naville et al. 1999, 2001). The constructs which contain fragments between -1221 and - 1069 bp were prepared by appropriate digestions of the $\mathrm{p}(-2248 /+22)$ luc vector. Vectors containing mutated fragments were obtained using the QuickChange site-directed mutagenesis kit from Stratagene (Ozyme; Montigny-le-Bretonneux, France) and oligonucleotides containing the desired mutation (Table 1). For each construct, at least two different preparations were performed and the same vectors were used for both cell types to rule out plasmid preparation inequalities.

\section{Transient transfections and luciferase assays}

The day before transfection, cells were plated on six-well dishes at 600000 cells per well for BAC and B-Gran cells and 200000 cells per well for HEK293 in complete medium. Transfections were performed in serum-free medium without antibiotics using the lipofectAMINE PLUS reagent (Invitrogen) in the presence of $2 \mu \mathrm{g}$ DNA, following the method suggested by the manufacturer. Luciferase activity was measured 3 days after transfection as previously described (Naville et al. 1999). To assess transfection efficiency, cells were transfected with the pGL3 control vector which 
contains the SV40 promoter upstream of the luciferase gene. Moreover, in the first experiments, cells were co-transfected with the pRL-TK vector (Promega) which contains the Renilla luciferase reporter gene driven by the HSV-TK promoter, in order to normalize transfection efficiencies.

Statistical analysis was performed with Student's $t$-test for comparison between two groups. The null hypothesis was rejected when $P>0 \cdot 05$ was obtained.

\section{Electrophoretic mobility shift assay (EMSA)}

Crude nuclear protein extracts were prepared from BAC and B-Gran cells as described by Schreiber et al. (1989) and the protein concentrations were determined by the BCA protein assay system (Pierce Chemical, Montluçon, France). Doublestranded oligonucleotides (Table 1) were labelled by T4 polynucleotide kinase (Invitrogen) using $\left[\gamma^{32}\right.$-P $]$ ATP (Amersham France, Saclay, France) and incubated with nuclear extracts as previously described (Naville et al. 1999). Poly (dI.dC) (dI.dG) (Amersham France) was used as non-specific competitor to reduce non-specific binding to the probe. For the competition assays, a molar excess of 200-fold of unlabelled double-stranded oligonucleotides was added to the reaction mixture. The AP4sv oligonucleotide was designed from the sequence described by Mermod et al. (1988). The resulting DNA-protein complexes were analyzed by electrophoresis as previously described (Naville et al. 1999) and dried gels were exposed to Kodak BioMax MR film (Sigma-Aldrich, Saint-Quentin Fallavier, France).

\section{RT-PCR analysis}

In order to determine the presence of activating enhancer-binding protein 4 (AP-4) mRNA in the adrenal gland and in granulosa cells, total RNA was prepared from various tissues or cells: BAC, B-Gran cells, human adrenocortical H295R cell line, human adrenal tissue and human granulosa cells using the method of Chomczynski \& Sacchi (1987). Human adult adrenals were obtained after organ removal for transplantation from brain-dead patients, with the approval of the ethical committee of the Hospices Civils de Lyon.

Reverse transcription was performed using total RNA. First-strand cDNA was prepared with $1 \mu \mathrm{g}$

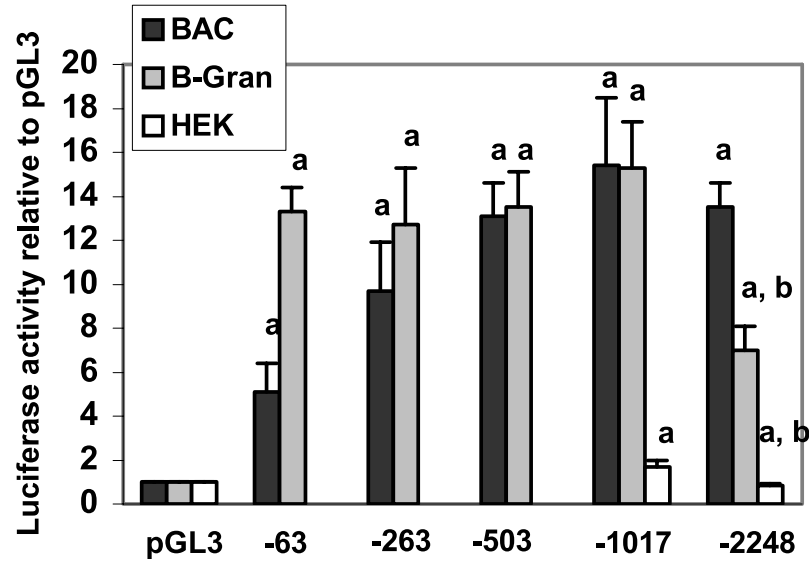

Figure 1 Deletion analysis of constitutive $h M C 2 R$ promoter activity in BAC, B-Gran and HEK293 (HEK) cells. Relative luciferase activities are expressed as fold increase over pGL3 basic. Values represents means \pm S.E.M. of three to six different experiments performed in quadruplicate using at least two different plasmid preparations for each construct. 'a' indicates values significantly different from those obtained with the promotorless vector pGL3 basic $(P<0.01)$, 'b' values are significantly different from those obtained with the $\mathrm{p}(-1017 /+22)$ luc vector $(P<0.02)$.

RNA using M-MLV reverse transcriptase (Invitrogen) according to the manufacturer's protocol. One microlitre of reverse-transcribed cDNA was used for PCR reactions.

The primers used in the PCR reaction (38 cycles) were designed to amplify part $(270 \mathrm{bp})$ of the human coding sequence (Genbank accession number: NM_003223) as the bovine sequence was not available.

\section{Results}

\section{Deletion and mutation analyses of the $h M C 2 R$ promoter in adrenal and non-adrenal cells}

The transfection efficiencies were equivalent in BAC and B-Gran cells as demonstrated by using the pGL3 control vector: $307 \cdot 7 \pm 69 \cdot 3-$ and $421 \cdot 9 \pm 116 \cdot 0$-fold stimulation over pGL3 $(n=5)$ for BAC and B-Gran cells respectively. We used series of deleted fragments of the $h M C 2 R$ gene promoter (from -63 to $-2248 \mathrm{bp}$ upstream of the transcription start site) inserted into a vector with luciferase gene as reporter, to transfect three different cell types (Fig. 1): cells expressing $h M C 2 R$ and $S F-1$ genes (BAC), cells expressing $S F-1$ gene 
but not $h M C 2 R$ gene (B-Gran cells) and cells expressing neither $S F-1$ nor $h M C 2 R$ genes (HEK293). In BAC cells, luciferase activity increased by 5 -fold as compared with pGL3 basic, using the shortest construct $\mathrm{p}(-63 /+22)$ luc. After transfection with longer constructs, constitutive activities were significantly increased with a plateau obtained using constructs containing $503 \mathrm{bp}$ of the promoter and more. On the contrary, in B-Gran cells all the constructs produced the same luciferase activities (around 13-fold increase above the level obtained with pGL3 basic) except the longest construction, $\mathrm{p}(-2248 /+22)$ luc, which produced a 2-fold decreased activity as compared with the level of activity obtained with $\mathrm{p}(-1017 /+22)$ luc vector. This would imply that part of inhibition of the $h M C 2 R$ gene expression in B-Gran cells is dependent on cis-acting sequence(s) present between -1017 and -2248 bp upstream of the transcription start site. For HEK293 cells, the constitutive expression of $h M C 2 R$ gene was very low $(1 \cdot 7$-fold increase using the $\mathrm{p}(-1017 /+22)$ luc vector) and even decreased when the cells were transfected with $\mathrm{p}(-2248 /+22)$ luc (Fig. 1). As these non-steroidogenic cells do not express SF-1, could this factor be responsible for the constitutive expression of the $h M C 2 R$ gene observed in B-Gran cells using constructs containing up to $-1017 \mathrm{bp}$ ? Indeed, previous studies have already demonstrated that SF-1 is responsible for basal expression of the $h M C 2 R$ gene in mouse $\mathrm{Y} 1$ and human adrenocortical H295R cell lines (Marchal et al. 1998, Naville et al. 1999).

\section{Role of SF-1 in tissue-specific expression}

To answer the question as to the role of SF-1 in tissue-specific expression, we mutated the core sequence of the three SF-1-binding sites in the context of either $\mathrm{p}(-263 /+22)$ luc or $\mathrm{p}(-1017 /$ +22 )luc (Naville et al. 1999). These sites are located at $-35,-98$ and -209 bp from the transcription start site. As shown in Fig. 2A, mutation of the SF-1-binding sites induced a decrease of basal luciferase activity in BAC cells. This decrease was more pronounced when the mutations were induced within the longer construct $(60 \%)$ compared with the mutated $\mathrm{p}(-263 /+22)$ luc vector $(44 \%)$. On the contrary, there was no change of activity in B-Gran cells using mutated $\mathrm{p}(-1017$ / +22)luc and even a slight, but non-significant,

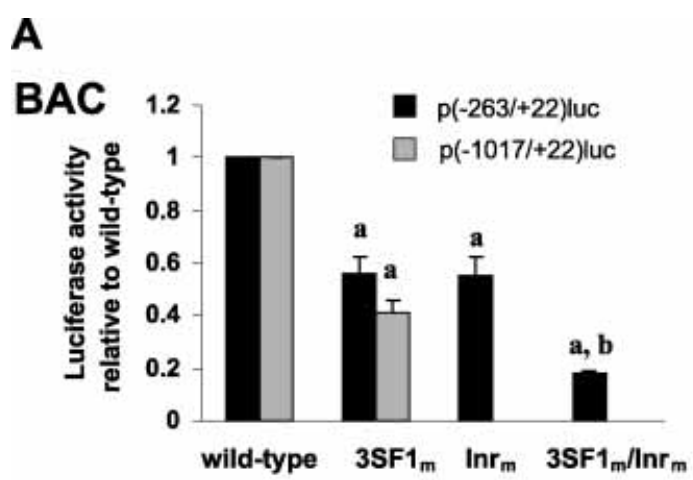

B

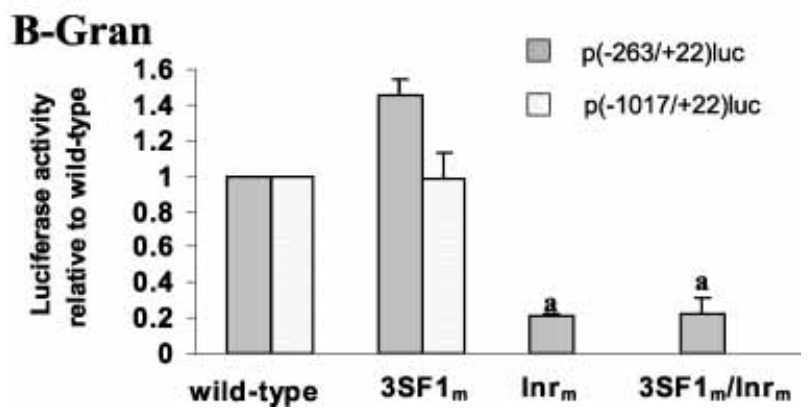

Figure 2 Effect of mutation of SF-1-binding sites (SF1 $\left.1_{m}\right)$ and/or Inr $\left(\mathrm{Inr}_{\mathrm{m}}\right)$ on constitutive hMC2R promoter activity in BAC and B-Gran cells. Relative luciferase activities are expressed relative to either $p(-263 /+22)$ luc or $p(-1017 /+22)$ luc vectors. Values represent means \pm S.E.M. of at least three different experiments performed in quadruplicate using at least two different plasmid preparations for each construct. 'a' indicates values significantly different from those obtained with the corresponding wild-type vector $(P<0.01)$, 'b' indicates values significantly different from those obtained with $p(-263 /+22)$ luc vector carrying mutations on the three SF1-binding sites $\left(3 \mathrm{SF} 1_{\mathrm{m}}\right)(P<0.01)$.

increase of the activity when using mutated $\mathrm{p}(-263 /+22)$ luc (Fig. 2B). Nevertheless, SF-1 expressed in granulosa cells as in BAC cells was able to bind the three sites present in the $h M C 2 R$ gene promoter using EMSA (data not shown), indicating that this binding was not sufficient to permit efficient expression of the $h M C 2 R$ gene in B-Gran cells. All these results would imply that SF-1 was partly involved in the basal adrenalspecific expression of $h M C 2 R$ in BAC cells, but not in the $h M C 2 R$ gene expression obtained in non-adrenal cells using short fragments of the $h M C 2 R$ gene promoter. Thus, the question arises as 
to which proximal region could allow this atypical expression.

The presence of an initiator element (Inr) in the $h M C 2 R$ gene promoter, overlapping the transcription start site, has been described previously (Naville et al. 1997). When mutated (Table 1) in the context of $\mathrm{p}(-263 /+22)$ luc (Fig. 2), there was a dramatic inhibition of luciferase activity obtained using B-Gran cells (80\% decrease; Fig. 2B). The decrease was less pronounced in BAC cells (45\%). A combination of mutations (Inr mut/3SF1 mut) intensified the inhibition of expression in BAC but not in B-Gran cells, when compared with the value obtained with the Inr mut vector. Taken together, these results demonstrated that the atypical expression of $h M C 2 R$ gene in B-Gran cells using proximal promoter could be explained mostly by the presence of the Inr element, whereas SF-1-binding sites play no major role.

\section{Involvement of one E-box-containing element in the partial repression of $h M C 2 R$ gene expression}

From the results described above, we could postulate that other factors which bind sequences located between -1017 and $-2248 \mathrm{bp}$ are involved in this tissue-specific expression (Fig. 1). These sequences could be further restricted to a region between $-1069 \mathrm{bp}$ and $-1017 \mathrm{bp}$ using other deleted constructs (Fig. 3A). After transfection with the $\mathrm{p}(-1069 /+22)$ luc vector, the basal luciferase activity relative to $\mathrm{p}(-1017 /+22)$ luc vector was significantly $(P<0.01)$ increased by $45 \%$ in BAC but, on the contrary, decreased by $40 \%$ in B-Gran cells. This indicates a strong difference (about 60\%) in luciferase activity between BAC and B-Gran cells using this construct (Fig. 3A). Similar results were obtained using vectors containing fragments up to $1221 \mathrm{bp}$ of the promoter. In the sequence between - 1069 and - 1017 bp, several putative binding sites for known transcription factors are present. Interestingly, a consensus E-box (CAGGTG) is located at - 1020 bp upstream of the transcription start site and therefore is truncated in the $\mathrm{p}(-1017 /$ +22)luc vector (Fig. 3B). By directed mutagenesis, this E-box was completely disrupted (Table 1) in the context of the $\mathrm{p}(-1221 /+22)$ luc vector. After transfection of this mutated construct, basal luciferase activity was differentially modified depending on the cell type: decreased in BAC and increased in B-Gran cells to values which were not significantly different from those obtained with $\mathrm{p}(-1017 /+22)$ luc vector (Fig. 3A). Differences obtained in luciferase activities using $\mathrm{p}(-1221 /$ +22)luc vector compared with $\mathrm{p}(-1017 /+22)$ luc vector were then greatly reduced between $\mathrm{BAC}$ and B-Gran cells when the E-box was mutated. These results would be in favour of an inhibitory factor present in B-Gran cells that bound to the E-box and would be partially responsible for the absence of expression of the $h M C 2 R$ gene in B-Gran cells. On the contrary, factors which bound the E-box in fasciculata-reticularis cells could have an activating function.

Other systematic mutations have been introduced in the context of the $p(-1221 /+22)$ luc vector between - 1069 and $-1017 \mathrm{bp}$, but only one mutation (Table 1) called mut Oc (mutation in a putative octamer (Oct)-binding site overlapping the E-box; Fig. 3B) changed the basal activities in BAC and B-Gran cells, giving similar results to those obtained using a vector mutated within the E-box (Fig. 3A). These results suggested that this region was also involved in the inhibition of the expression of the $h M C 2 R$ gene in B-Gran cells.

\section{Analysis of the E-box-containing region by EMSA}

From the results above, we can conclude that the region - 1069/ - 1017 seems to contain silencer element(s) which would bind a repressor present in granulosa cells and partially prevent the expression of $h M C 2 R$ gene in these cells, whereas a factor with activating function would bind to this region in $\mathrm{BAC}$ cells. It was therefore interesting to investigate this element further. We used the oligonucleotide $\mathrm{SpE}(-1036 /-1003$ in Table 1) containing the E-box as probe in a gel shift assay using nuclear extracts prepared from BAC and B-Gran cells in primary cultures. As shown in Fig. 4, several complexes were obtained using each cell type and the patterns were different depending on the cell type. Complex 'c' migrated at the same mobility for both cell extracts but was more intense using B-Gran cell extracts. Complexes 'b' and 'd' were specifically formed with BAC and B-Gran cell extracts respectively. Complex 'a' was in fact a composite of two different complexes in both cell types with band 'al' much less pronounced using 


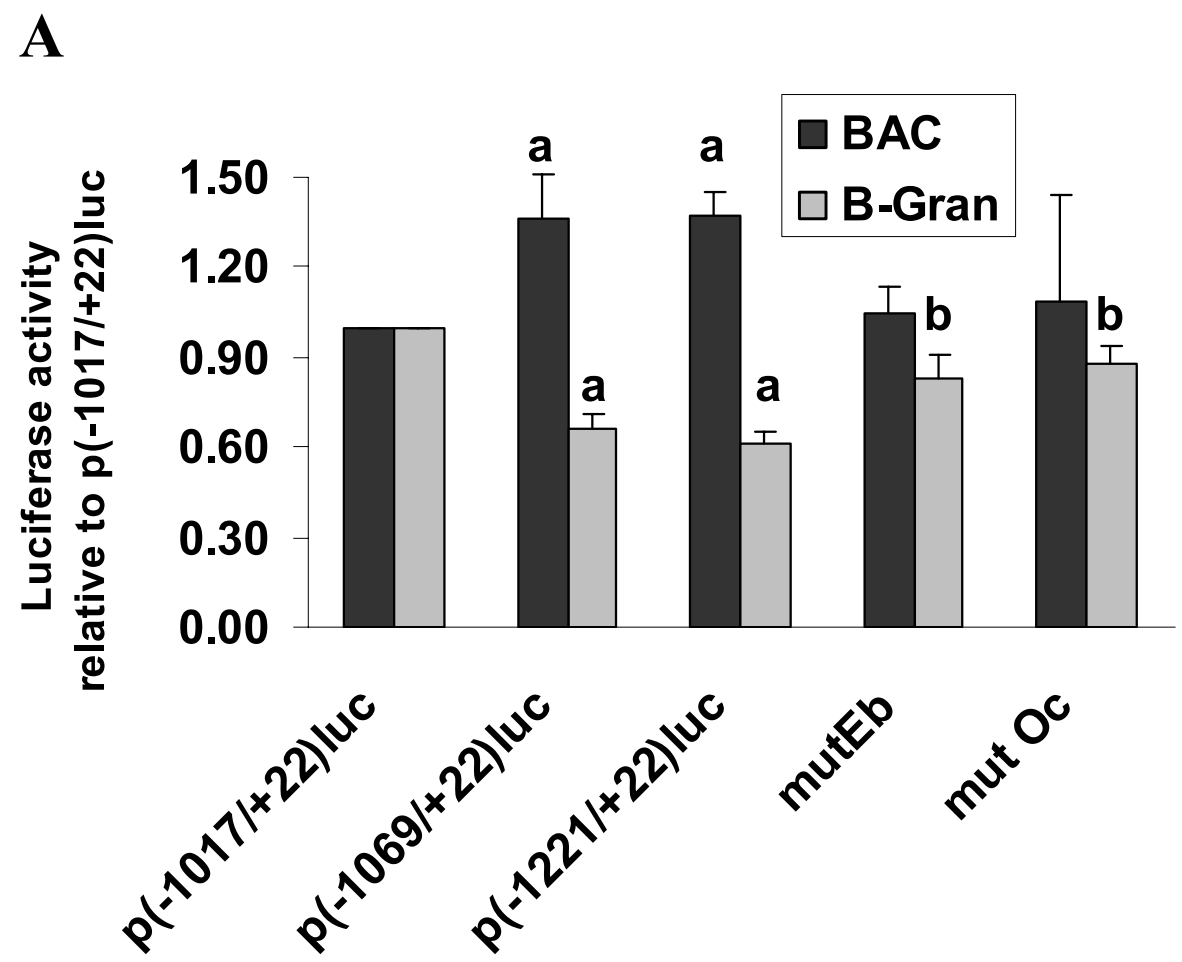

B

$-1221$

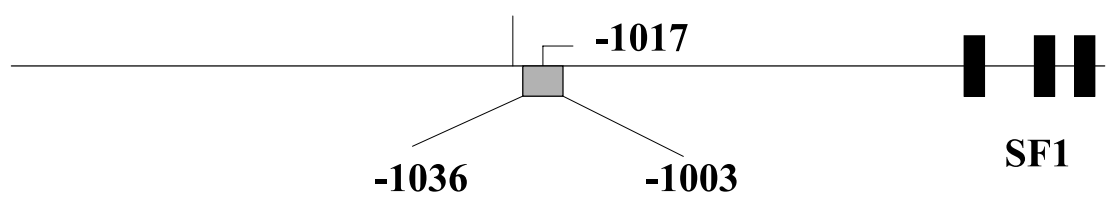

gtggaacgccgggtttcagctgcagggcatgtt

E-box

\section{Oct-1}

Figure 3 (A) Delimitation of one region involved in adrenal-specific expression of $h M C 2 R$. Relative luciferase activities are expressed relatively to $p(-1017 /+22)$ luc vector. MutEb and mut Oc vectors correspond to mutated $p(-1221 /+22)$ luc vectors (Table 1). Values represents means \pm S.E.M. of three to nine different experiments performed in quadruplicate using at least two different plasmid preparations for each construct. ' $a$ ' indicates values significantly different from those obtained with the $p(-1017 /+22)$ luc vector $(P<0 \cdot 01)$, 'b' values are significantly different from those obtained with the $p(-1221 /+22)$ luc vector $(P<0.05)$. (B) Schematic representation of the $h M C 2 R$ gene. The E-box and region mutated in Oct-1 site (region 7) are in bold. 


\section{BAC B-Gran}

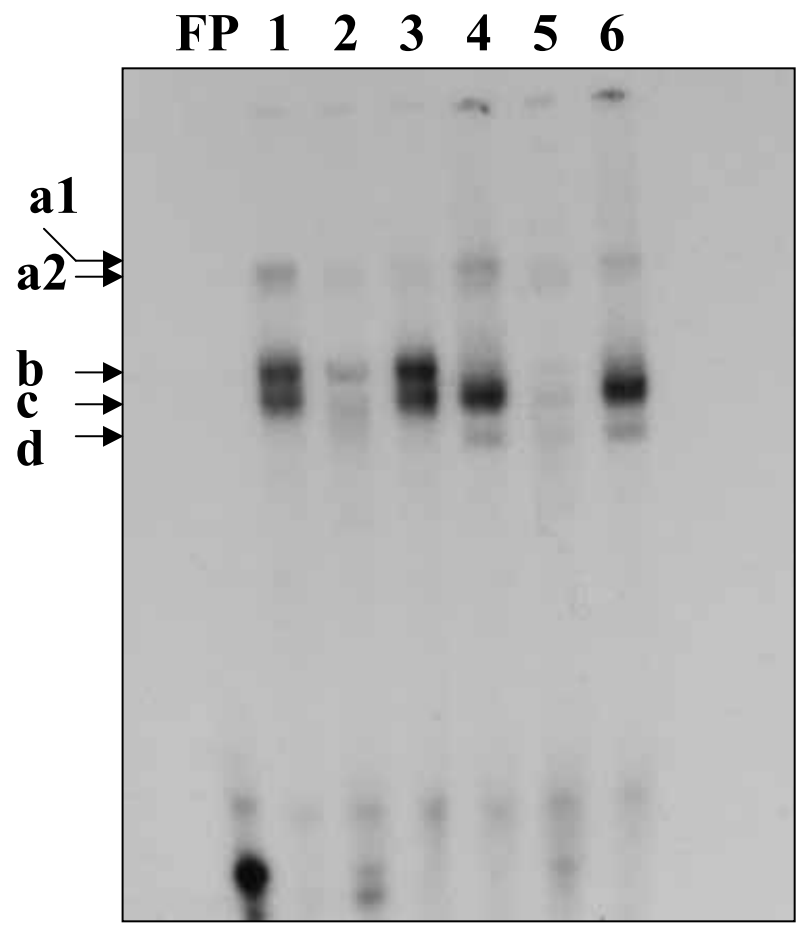

Figure $4 \mathrm{Gel}$ shift assay using $-1036 /-1003$ probe. Gel shift was performed with nuclear extracts isolated from BAC and B-Gran cells, in the presence of the labelled probe SpE alone (lanes 1 and 4) or in the additional presence of a 200 -fold excess of unlabelled probe $\mathrm{SpE}$ (lanes 2 and 5) or of a 200 -fold excess of mutated SpE mut Eb (lanes 3 and 6). FP, free probe. In this figure, the bands corresponding to the unbound probe have been lost due to the long run performed to better separate the different bands.

BAC extracts or even absent in some gel shift experiments (Figs 5 and 6), when band 'a2' was mostly present in BAC nuclear extracts (Fig. 6). All nuclear proteins are specifically bound to this DNA sequence as the intensities of the bands were highly reduced after incubation with an excess of unlabelled SpE probe (Fig. 4). In the presence of an excess of $\mathrm{SpE}$ mut $\mathrm{Eb}$ (Table 1), where the E-box was mutated, band 'a2' was decreased using BAC cell nuclear extracts only but there was no modification of bands 'al', 'b', 'c' and 'd' using both BAC and B-Gran cell extracts. This would imply that the specific formation of these last complexes needs a conserved E-box. To sum up these results, using the SpE probe, a complex ' $b$ '

\section{5}

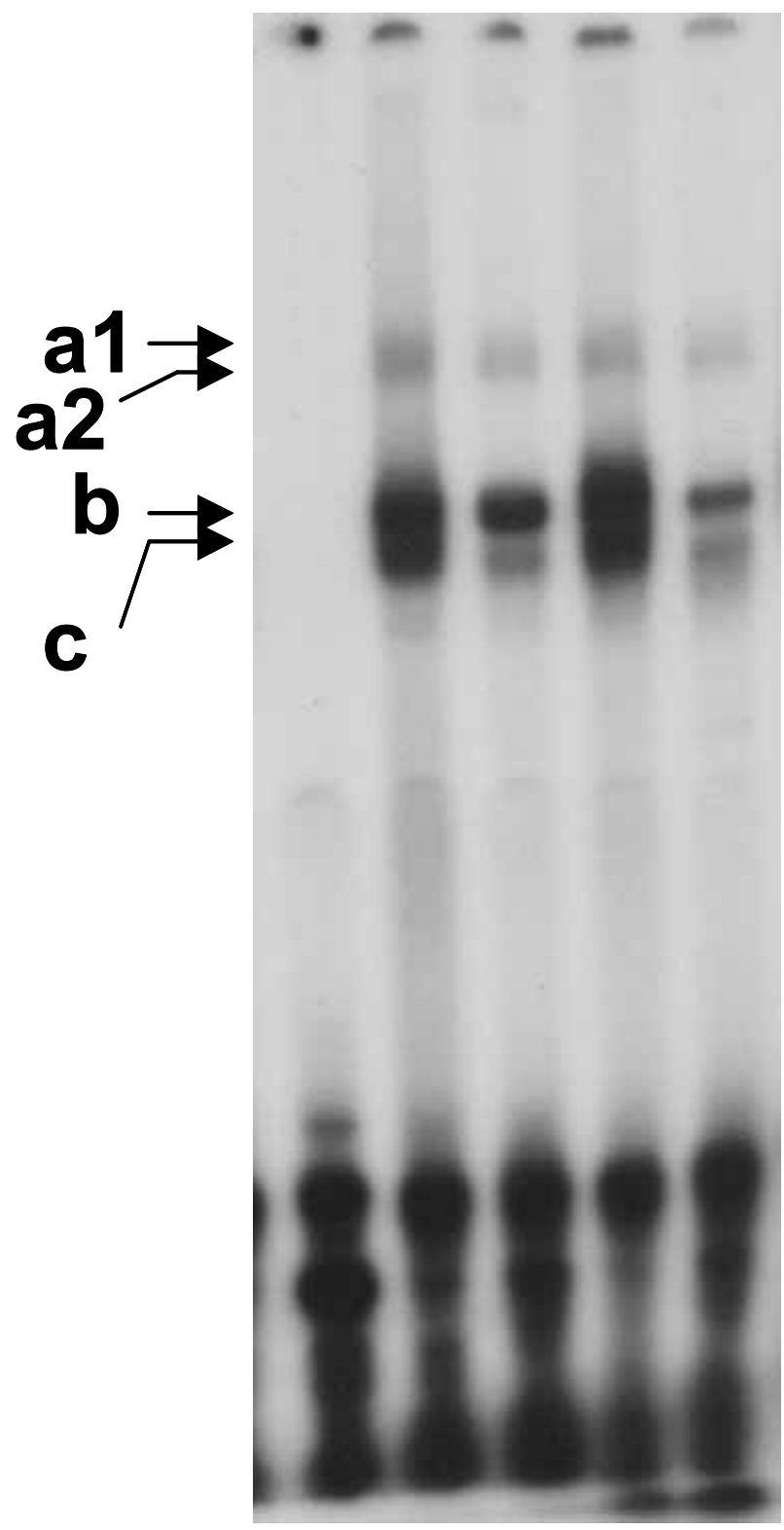

Figure 5 Effect of ACTH on binding to the $-1036 /-1003$ probe. Gel shift was performed using the labelled SpE probe, in the presence of nuclear extracts isolated from BAC cells treated (lanes 4 and 5 ) or not (lanes 2 and 3 ) with $10^{-9} \mathrm{M} \mathrm{ACTH}$. Lanes 3 and 5 were performed in the additional presence of an excess of unlabelled SpE. Lane 1 corresponds to the free probe.

was obtained specifically using BAC cell extracts, when two different complexes, 'al' and 'd', appeared specifically using B-Gran cell 


\section{BAC}

\section{B-Gran}

\section{$\begin{array}{llllllllllllllllll}1 & \text { FP } & 2 & 3 & 4 & \text { FP } & 5 & 6 & 7 & 1 & \text { FP } & 2 & 3 & 4 & \text { FP } & 5 & 6 & 7\end{array}$}

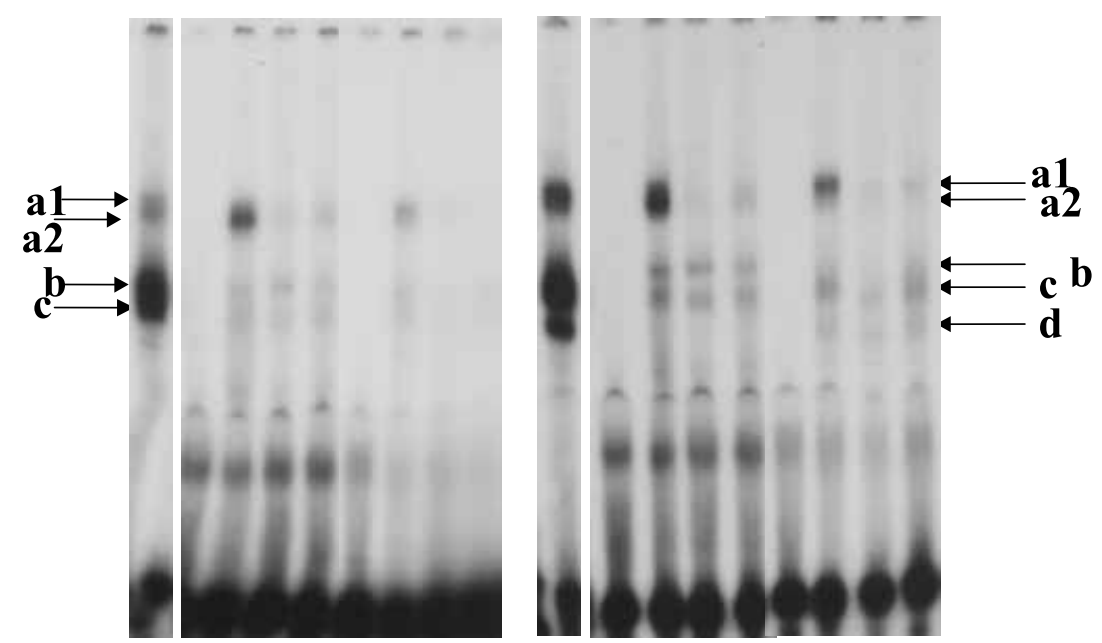

Figure 6 Gel shift assays using mutated $-1036 /-1003$ probes. Gel shift assays were performed with nuclear extracts isolated from BAC and B-Gran cells, in the presence of the labelled probe SpE alone (lane 1) or in the presence of labelled SpE mut Eb (lanes 2-4) or labelled mut Oc (lanes $5-7$ ). In lanes 3 and 6 , gel shift was performed in the additional presence of a 200-fold excess of unlabelled probe SpE, in lane 4 in the additional presence of an excess of unlabelled SpE mut Eb and in lane 7 in the additional presence of an excess of unlabelled mut Oc. FP, free probe.

extracts. However, the formation of these different cell-specific complexes needed a conserved E-box.

Complexes 'b' and ' $c$ ' are the major ones obtained using BAC nuclear extracts. The adrenalspecific complex ' $b$ ' was positively regulated by a 48-h treatment in the presence of $10^{-9} \mathrm{M}$ ACTH, when complexes ' $a$ ' and ' $c$ ' were not changed (Fig. 5). Quantification of the bands indicated a 2-fold increase of the complex ' $b$ ' intensity after ACTH treatment $(1 \cdot 9 \pm 0 \cdot 4$-fold, using three different experiments).

When the mutated oligonucleotide SpE mut $\mathrm{Eb}$ was used as a labelled probe (Fig. 6) the intensity of the band 'al' was greatly reduced in B-Gran cell extracts whereas the intensity of a lower band ('a2') increased. This complex 'a2' also increased in BAC cell extracts. The other bands ('b', 'c' and 'd') were not present using both cell extracts. These results confirmed that the formation of these complexes ' $b$ ' and 'c' for BAC cells and 'al', 'c' and 'd' for B-Gran cells needs a conserved E-box. On the contrary, when the oligonucleotide SpE mut Oc (Table 1) was used as probe only the band 'al' was present (Fig. 6).
Again, all the other bands ('a2', 'b', 'c' and 'd') were absent. Formation of these complexes ' $b$ ' and 'c' for BAC cells and 'c' and 'd' for B-Gran cells needed conservation of both the E-box and the Oct sequence whereas formation of complex 'al' needed a conserved E-box and a conserved Oct sequence was necessary for complex 'a2'.

It is known that upstream stimulatory factors (USF)- 1 and USF-2 can bind to an E-box (CACGTG). Antibodies against either USF-1 or USF-2 did not generate super-shifted bands and did not diminish the intensity of bands in gel shift assay (data not shown), indicating that these factors were not part of the different complexes. Another factor (AP-4) has been described to bind the same sequence as the E-box found here (CAGCTG). Instead of using AP-4 antibodies, which are not commercially available, we used an oligonucleotide previously mentioned to bind this factor (Mermod et al. 1988) as unlabelled competitor. This AP4sv oligonucleotide (Table 1) was able to displace the complexes 'al' present in B-Gran cell extracts (Fig. 7) indicating that the AP-4 transcription factor 


\section{BAC}

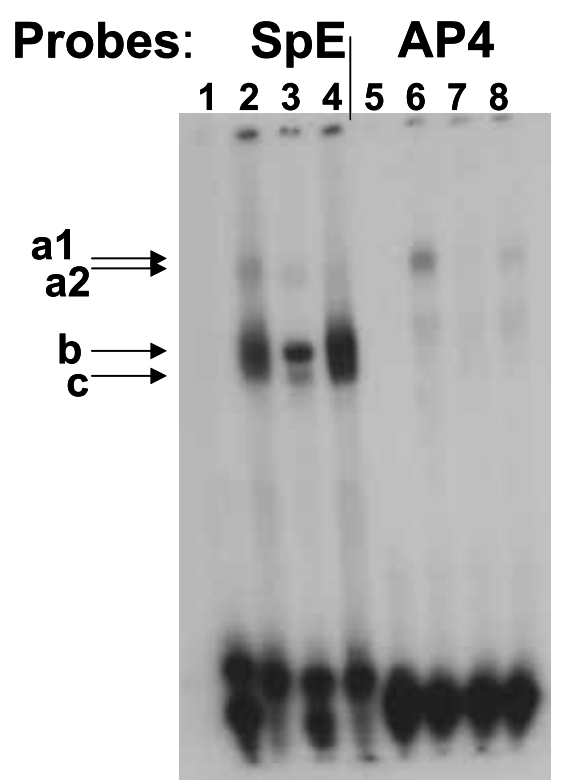

B-Gran

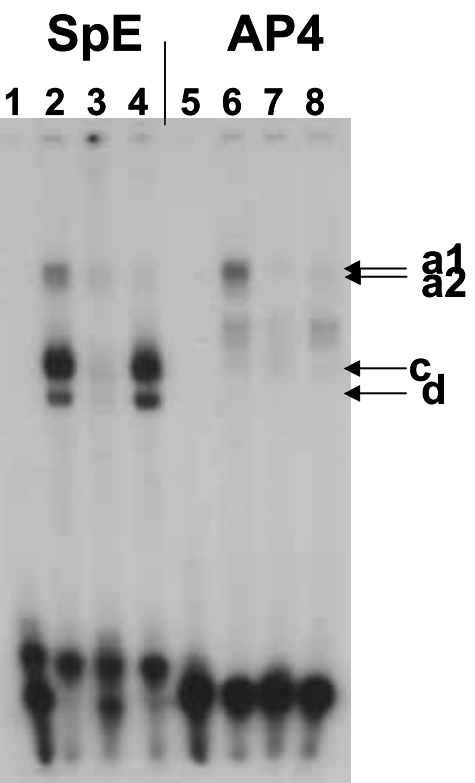

Figure 7 Gel shift assay using the oligonucleotide AP4sv as competitor and probe. Gel shift assays were performed with nuclear extracts isolated from BAC and B-Gran cells, using as probe either labelled SpE (lanes 1-4) or labelled AP-4 (lanes 5-8), in the additional presence of an excess of unlabelled SpE (lanes 3 and 8) or unlabelled AP4sv containing an AP-4 binding sequence (lanes 4 and 7 ). Lanes 1 and 5 correspond to the free probes.

(or a related factor) could be part of the 'al' complex. Indeed, AP-4 was expressed in both BAC and B-Gran cells as demonstated by RT-PCR (Fig. 8A). AP-4 mRNA was also present in human adrenal tissue, in the human adrenocortical cell line H295R and in human granulosa cells (Fig. 8B).
The AP4sv was also used as a labelled probe in the presence of nuclear extracts prepared from both BAC and B-Gran cells. A unique labelled complex was observed for both cell extracts with a mobility corresponding to the 'al' band even in BAC cells, whereas this band was almost absent using nuclear
0 BAC B-Gr

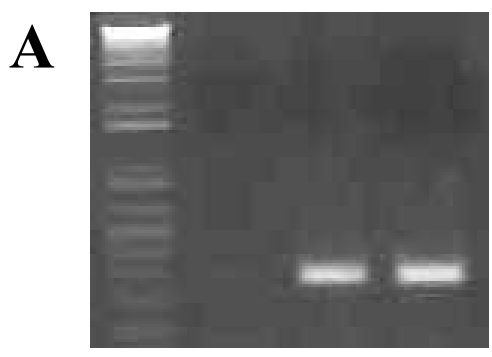

0 H-Gr H295R HA

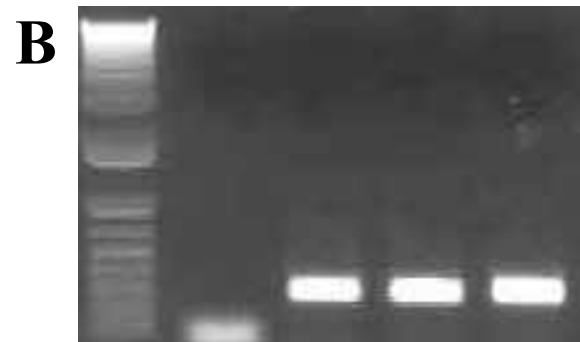

Figure 8 RT-PCR analysis of bovine and human tissues. Total RNA was isolated from BAC and B-Gran (B-Gr) cells $(A)$ or human granulosa $(\mathrm{H}-\mathrm{Gr})$ cells, H295R and human adrenal tissue (HA). (B) These RNA were analyzed by RT-PCR using oligonucleotides specific for the human AP-4 mRNA. Lane 0 indicates the absence of cDNA in the PCR mixture. 
extracts prepared from this latter cell type in the presence of the labelled $\mathrm{SpE}$ probe. These results confirmed that the BAC cell extracts contain AP-4 but that binding of protein(s) contained in complex 'b' (absent in B-Gran cell extract) could prevent the AP-4 binding to the SpE probe.

\section{Discussion}

To investigate the question as to which cis-acting elements of the $h M C 2 R$ gene promoter are responsible for tissue-specific expression, we compared activities obtained after transient transfection of two types of steroidogenic cells. The models used were primary cultures of BAC and B-Gran cells. In fact we could not dispose easily of the equivalent human cells and there is no human non-adrenal cell line with well-preserved steroidogenic functions. Moreover, BAC cells display similar luciferase activities to H295R cells used previously (Naville et al. 2001) when transfected with deleted fragments of the $h M C 2 R$ gene promoter inserted upstream of the luciferase gene.

The expression of the $h M C 2 R$ gene seems to be controlled at several levels. The first one involves proximal sites present on the gene promoter which bind SF-1, as mutation of these sites induced a $60 \%$ decrease of basal expression in BAC cells. A similar decrease has been obtained using the mouse MC2R promoter displaying a mutated - 25-SF-1binding site (Cammas et al. 1997). This factor is an important trans-activator in the expression of numerous genes in both adrenal and non-adrenal steroidogenic cells. In the adrenal, besides the expression of the $M C 2 R$ gene (Cammas et al. 1997, Marchal et al. 1998, Naville et al. 1999), it controls the expression of steroidogenic enzymes such as cholesterol side-chain cleavage promoter (P450 scc) (Liu \& Simpson 1997), 17 $\alpha$-hydroxylase/c17-20 lyase (Zhang \& Mellon 1996) and 3 $\beta$ hydroxysteroid dehydrogenase (Leers-Sucheta et al. 1997) or other target genes such as steroidogenic acute regulatory protein (Sugarawa et al. 1997). In granulosa cells, SF-1 is involved in the regulation of expression of genes either expressed in granulosa and in adrenal cells such as P450 scc (Clemens et al. 1994) or expressed in granulosa cells but not in adrenal cells such as aromatase (Lynch et al. 1993). But, as reported here, the binding of SF-1 to its responsive element is not sufficient to permit trans-activation of the $M C 2 R$ gene expression in granulosa cells. In these cells, there was no difference in proximal $h M C 2 R$ gene promoter activity in the presence of either wild-type SF-1-binding sites or mutated ones. The presence of the Inr element could explain the $h M C 2 R$ gene expression retained by B-Gran cells after transfection with constructs containing only the proximal region downstream of position $-1017 \mathrm{bp}$ of the $h M C 2 R$ gene promoter. This absence of transactivation by SF-1 in B-Gran cells at the $h M C 2 R$ gene promoter level could be due to interaction with some co-repressor in these cells. Indeed, it is well known that SF-1 can interact with different cofactors, either co-activators such as CREB binding protein, cAMP responsive element binding protein (CREB)-binding protein (Carlone \& Richards 1997) or co-repressors such as Dax-1 and nuclear corepressor (Crawford et al. 1998) which can modulate gene expression. SF-1 is also able to interact with several transcription factors such as selective promotor factor-1 (Liu \& Simpson 1997). In the case of the $h M C 2 R$ gene, disruption of the SF-1-binding sites induced a more pronounced inhibition of expression when adrenal cells are transfected with a mutated $\mathrm{p}(-1017 /+22)$ luc vector $(60 \%$ inhibition) compared with mutated $\mathrm{p}(-263 /+22)$ luc vector $(44 \%$ inhibition $)$. These results are in favour of the existence of an interaction between SF-1 and other factor(s), which would bind sites present between -263 and - 1017, directly or through an intermediate protein. This activating factor may be present only in adrenal cells but not in granulosa or other non-adrenal steroidogenic cells. The tissue-specific recruitment of co-factors by SF-1 has been described in several cell types (Hammer \& Ingraham 1999). It is the case, in particular, of early growth response protein 1 in pituitary gonadotropes (Halvorson et al. 1998) and Wilm's tumor-associated gene-1 (WT-1) in gonads (Nachtigal et al. 1998). A crucial role of SF-1 in tissue-specific expression because of interactions with various trancriptional regulators such as WT-1 (Nachtigal et al. 1998), SRY-related HMG-box, gene 9 (DeSantaBarbara et al. 1998) and GATA-4 (Tremblay \& Viger 1999) has been demonstrated for the Müllerian-inhibiting substance (MIS) gene. The above results indicate the involvement of SF-1 in basal cell-specific transcription of the $h M C 2 R$ gene in adrenal cells. 
In addition to this positive control by SF-1 on $h M C 2 R$ gene expression in adrenal cells, other regions are involved in negative control in non-adrenal cells. Indeed, studies by transient transfections of deleted fragments of the $h M C 2 R$ gene promoter have allowed the delineation of another, more distal, region that partially controls cell-specific transcription of this gene. This region - 1017/ - 1069 contains a particular sequence, CAGGTG, corresponding to an E-box. Mutation of this site induced a partial loss of the inhibition of the $h M C 2 R$ gene expression in B-Gran cells and a concomitant decrease of $h M C 2 R$ gene expression in BAC cells. The same element could then be involved in repression or activation of $h M C 2 R$ gene expression in B-Gran and BAC cells respectively, through binding of different factors. The binding of a factor to a region between -1236 and $-908 \mathrm{bp}$ of the mouse $M C 2 R$ gene promoter and acting as a repressor in non-adrenal cells has been postulated by Cammas et al. (1997) but no further studies have been done.

The involvement of proteins that bind to an E-box in tissue-specific expression has been described for numerous genes. They play a role in transcription either as activators or as repressors. For example there are two E-boxes in rat skeletal muscle type 1 sodium channel (SkMI) gene (Kraner et al. 1998). The proximal site which binds a transcription factor belonging to the MyoD family controls the positive expression of the gene in muscle cells, when the more distal site plays a role in the repression of SkM1 expression in non-muscle cells. Proteins that bind to hexanucleotide E-boxes (CANNTG) belongs to the basic helix-loop-helix protein (bHLH) family which is characterized by the presence of two domains: a conserved helix-loop-helix domain allows homo- or heterodimerization and interactions with other proteins (Murre et al. 1994) and a basic domain, the paired basic domain permitting binding to the specific DNA sequence. E-box-binding proteins have, in particular, been shown to interact with factors involved in the oxidative stress or in hypoxia $(\mathrm{Li}$ et al. 1998, St-Pierre et al. 2002).

In our model, the presence of three different protein complexes appeared to depend on the integrity of the E-box in EMSA studies. Complex 'b' was present only using BAC cell extracts, complex 'd' only using B-Gran cell extracts, whereas complex 'c' was present in both cell types but at a higher level in B-Gran cells than in BAC. The intensity of complex 'al' was also much higher using B-Gran cell extracts than using BAC cell extracts and competition assays demonstrated that the transcription factor AP-4 was part of this complex. This ubiquitously expressed transcription factor belongs to the bHLH family and more specifically to the bHLH-Zip subfamily. The bHLH-Zip proteins contain another dimerization domain, the leucine zipper (Littlewood \& Evan 1995). As such, AP-4 could potentially form dimers with various transcription factors. It was first identified as a ligand for the simian virus SV40 enhancer (Mermod et al. 1988) and described as a transcription activator in synergy with AP-1. To date it has mostly been shown to bind enhancer sequences present in several genes such as human proenkephalin (Comb et al. 1988) but it could also be involved in repressor activities (Gui et al. 1998).

As AP-4 is an ubiquitous protein it must interact with cell-specific proteins or permit the binding of these proteins to their target site(s). In the case of the $h M C 2 R$ gene, it probably interacts with a repressing factor present in non-adrenal cells and/or permits binding in the vicinity of a protein with inhibitory function (B-Gran specific complex ' $d$ ' in our study), possibly through an intermediate protein as cofactor (Fig. 9). Disruption of the E-box will then prevent formation of both AP-4-containing 'al' complex and ' $d$ ' complex and increase the expression of the $h M C 2 R$ gene in non-adrenal cells. The formation of a complex between bHLH proteins and cofactors has been demonstrated for several gene promoters. The neuro-specific transcription of the $v g f$ gene is dependent on a tripartite region involving an E-box, a CCAAT sequence and a CRE site (Mandolesi et al. 2002). The proteins which bind to these sites form a multiprotein complex with p300 coactivator.

It is known that the expression of the $h M C 2 R$ gene is positively regulated by ACTH (Lebrethon et al. 1994). In BAC cell extracts, only the binding of proteins belonging to the major complex ' $b$ ' was increased (by 2-fold) after ACTH treatment. This increase is in the same order of magnitude as the fold stimulation obtained on cAMP-induced activation of the $h M C 2 R$ gene promoter (Naville et al. 1999). This adrenal-specific 'b' protein could act by preventing the binding of $\mathrm{AP}-4$ and/or of the repressing factor (part of complex ' $d$ ') to their respective binding site, this effect being even more 


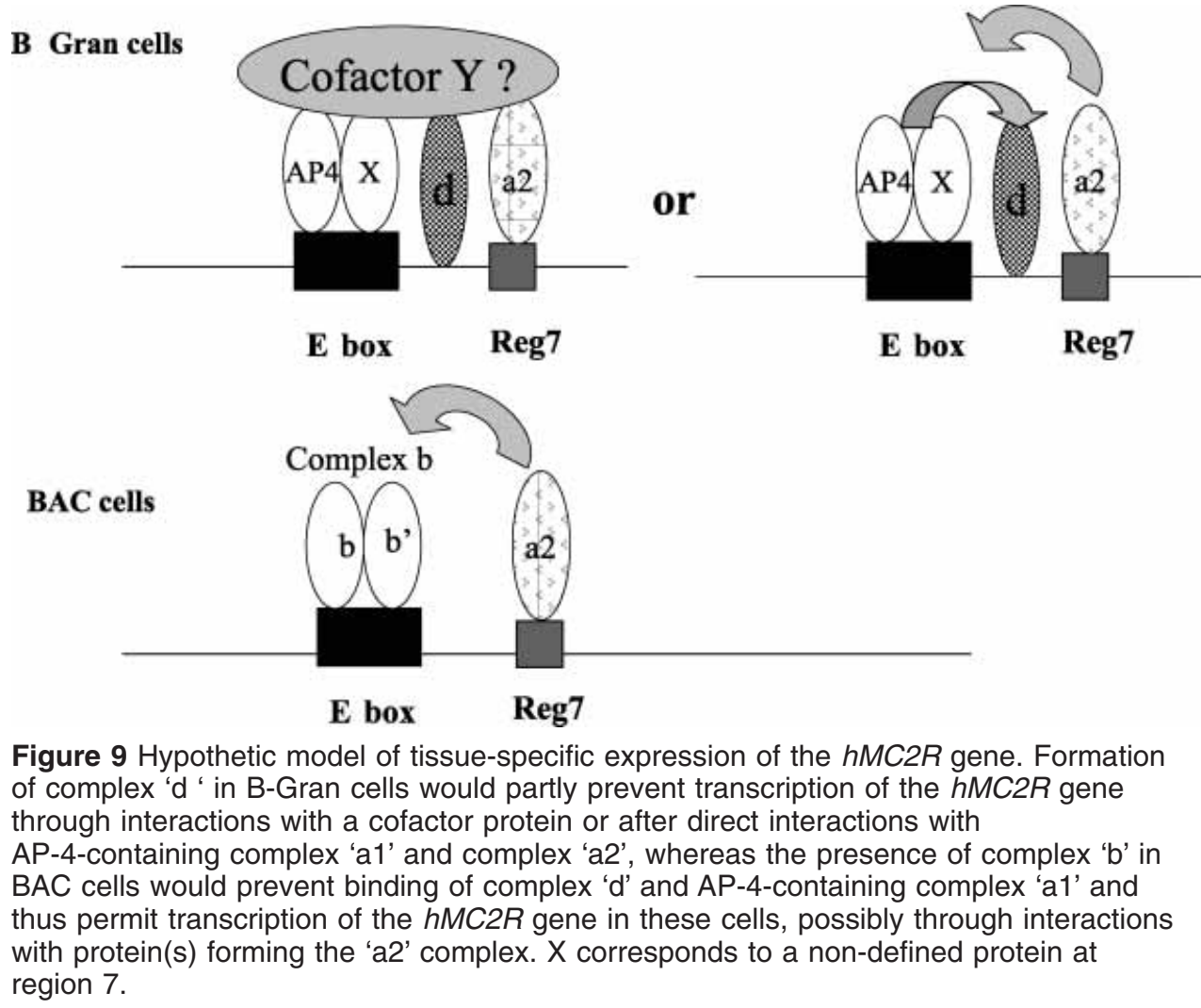

pronounced after ACTH treatment (Fig. 9). The binding of this protein ' $\mathrm{b}$ ' was also dependent on the integrity of the E-box possibly because of a direct binding to this site (Fig. 9).

Downstream of the E-box, there is an additional element, the overlapping putative Oct-binding site, which bound proteins 'a2' independently of the E-box. Its integrity was also required for the presence of 'b', 'c' and 'd' complexes. It could then stabilize formation of a multiprotein complex, in particular in B-Gran cells (Fig. 9). In conclusion, we have show here that a proximal region in the $h M C 2 R$ gene promoter was involved in the partial inhibition of the $h M C 2 R$ gene expression in non-adrenal cells, but other more distal (upstream of position $-2248 \mathrm{bp}$ ) element(s) would be needed to completely prevent $h M C 2 R$ gene expression in these cells.

\section{Acknowledgements}

We thank Frédéric Volland for collection of bovine adrenals and ovaries, Hélène Cordonnier for the human granulosa cell preparation and W E Rainey (Dallas, TX, USA) for the generous gift of the H295R cell line. A B was supported by a Nestlé grant and by La Fondation de la Recherche Médicale. MD was a recipient of a fellowship from the Institut de Recherches Internationales Servier.

\section{References}

Boston BA \& Cone RD 1996 Characterization of melanocortin receptor subtype expression in murine adipose tissues and in the 3T3-L1 cell line. Endocrinology 137 2043-2050.

Cammas FM \& Clark AJL 1995 Tissue distribution of ACTH receptor messenger RNA. Fournal of Endocrinology 147 (Suppl) P11.

Cammas FM, Pullinger GD, Barker S \& Clark AJL 1997 The mouse adrenocorticotropin receptor gene: cloning and characterization of its promoter and evidence for a role of the orphan nuclear receptor steroidogenic factor 1. Molecular Endocrinology 11 867-876.

Carlone DL \& Richards JS 1997 Functional interactions, phosphorylation and levels of $3^{\prime} 5^{\prime}$-cyclic adenosine monophosphate-regulatory element binding protein and steroidogenic factor-1 mediate hormone-regulated and constitutive expression of aromatase in gonadal cells. Molecular Endocrinology 11 292-304. 
Chomczynski P \& Sacchi M 1987 Single-step method of RNA isolation by acid guanidium thiocyanate-phenol-chloroform extraction. Analytical Biochemistry 162 156-159.

Clemens JW, Lala DS, Parker KL \& Richards JS 1994 Steroidogenic factor-1 binding and transcriptional activity of the cholesterol side-chain cleavage promoter in rat granulosa cells. Endocrinology 134 1499-1508.

Comb M, Mermod N, Hyman SE, Pearlberg J, Ross ME \& Goodman, HM 1988 Proteins bound at adjacent DNA elements act synergistically to regulate human proenkephalin cAMP inducible transcription. EMBO Fournal 7 3793-3805.

Crawford PA, Dorn G, Sadovsky Y \& Milbrandt J 1998 Nuclear receptor Dax-1 recruits nuclear receptor corepressor N-CoR to steroidogenic factor 1. Molecular and Cellular Biology 18 2949-2956.

Cui Y, Narayanan CS, Zhou J \& Kumar A 1998 Exon-1 is involved in positive as well as negative regulation of human angiotensingen gene expression. Gene 224 97-107.

Derrien A, Langlois D \& Saez JM 1996 Expression and regulation of Gaq and Gal1 mRNAs and proteins in bovine adrenal cells. Molecular and Cellular Endocrinology 121 65-74.

DeSantaBarbara P, Bonneaud N, Boizet B, Desclozeaux M, Moniot B, Sudbeck P, Scherer G, Poulat F \& Berta P 1998 Direct interaction of SRY-related protein SOX9 and steroidogenic factor 1 regulates transcription of the human anti-Müllerian hormone gene. Molecular and Cellular Biology 18 6653-6665.

Grunfeld C, Hagman J, Sabin EAi, Buckley DI, Jones DS \& Ramachandran J 1985 Characterization of adrenocorticotropin receptors that appear when 3T3-Ll cells differentiate into adipocytes. Endocrinology 116 113-117.

Halvorson LM, Ito M, Jameson JL \& Chin WW 1998 Steroidogenic factor- 1 and early growth response protein 1 act through two composite DNA binding sites to regulate luteinizing hormone $\beta$-subunit gene expression. Fournal of Biological Chemistry 273 14712-14147.

Hammer GD \& Ingraham HA 1999 Steroidogenic factor-1: its role in endocrine organ development and differentiation. Frontiers in Neuroendocrinology 20 199-223.

Kraner SD, Rich MM, Kallen RG \& Barchi RL 1998 Two E-boxes are the focal point of muscle-specific skeletal muscle type $1 \mathrm{Na}+$ channel gene expression. Fournal of Biological Chemistry 273 11327-11334.

Lauber ME, Kagawa N, Waterman MR \& Simpson ER 1993 cAMP-dependent and tissue-specific expression of genes encoding steroidogenic enzymes in bovine luteal and granulosa cells in primary culture. Molecular and Cellular Endocrinology 93 227-233.

Lebrethon MC, Naville D, Bégeot M \& Saez JM 1994 Regulation of corticotrophin receptor number and messenger RNA in cultured human adrenocortical cells by corticotrophin and angiotensin II Fournal of Clinical Investigation 93 1828-1833.

Leers-Sucheta S, Morohashi K, Mason JI \& Melner MH 1997 Synergistic activation of the human type II $3 \beta$-hydroxysteroid dehydrogenase/ $\Delta 5-\Delta 4$ isomerase promoter by the transcrption factor steroidogenic factor-1/adrenal 4-binding protein and phorbol ester. Fournal of Biological Chemistry 272 7960-7967.

Li Q, Hu N, Daggett MAF, Chu WA, Bittel D, Johnson JA \& Andrews GK 1998 Participation of upstream factor (USF) in cadmium induction of the mouse metallothionein-I gene. Nucleic Acids Research 26 5182-5189.

Littlewood TD \& Evan GI 1995 Transcription factors 2: helix-loop-helix. Protein Profile 2 621-702.

Liu Z \& Simpson ER 1997 Steroidogenic factor 1 (SF-1) and Spl are required for regulation of bovine CYP1 $1 \mathrm{~A}$ gene expression in bovine luteal and adrenal Y1 cells. Molecular Endocrinology $\mathbf{9}$ 127-137.
Lynch JP, Lala DS, Peluso JJ, Luo W, Parker KL \& White BA 1993 Steroidogenic factor 1 , an orphan nuclear receptor, regulates the expression of the rat aromatase gene in gonadal tissues. Molecular Endocrinology 7 776-786.

Mandolesi G, Gargano S, Pennuto M, Illi B, Molfetta R, Soucek L, Mosca L, Levi A, Jucker R \& Nasi S 2002 NGF-dependent and tissue-specific transcription of vgf is regulated by a CREB-p300 and bHLH factor interaction. FEBS Letters $\mathbf{5 1 0} 50-56$.

Marchal R, Naville D, Durand P, Bégeot M \& Penhoat A 1998 A steroidogenic factor-1 binding element is essential for basal human ACTH receptor gene transcription. Biochemical and Biophysical Research Communications 247 28-32.

Mermod N, Williams TJ \& Tjian R 1988 Enhancer binding factors AP-4 and AP-1 act in concert to activate SV40 late transcription in vitro. Nature $332557-561$.

Murre C, Bain G, Van Dijk MA, Engel I, Furnari BA, Massari ME, Matthews JR, Quong MW, Rivera RR \& Stuiver MH 1994 Structure and function of helix-loop-helix proteins. Biochimica et Biophysica Acta 1218 129-135.

Nachtigal MW, Hirokawa Y, Enyeart-VanHouten DL, Flanagan JN, Hammer GD \& Ingraham HA 1998 Wilms' tumor 1 and Dax-1 modulate the orphan nuclear receptor SF-1 in sex-specific gene expression. Cell 93 445-454.

Naville D, Jaillard C, Barjhoux L, Durand P \& Bégeot M 1997 Genomic structure and promoter characterization of the human ACTH receptor gene. Biochemical and Biophysical Research Communications 230 7-12.

Naville D, Penhoat A, Durand P \& Bégeot M 1999 Three steroidogenic factor-1 binding elements are required for constitutive and cAMP-regulated expression of the human adrenocorticotropin receptor gene. Biochemical and Biophysical Research Communications 255 28-33.

Naville D, Bordet E, Berthelon M-C Durand P \& Bégeot M 2001 Activator protein-1 is necessary for angiotensin-II stimulation of human adrenocorticotropin receptor gene transcription. European Fournal of Biochemistry 268 1802-1810.

St-Pierre B, Flock G, Zacksenhaus E \& Egan SE 2002 Stra 13 homodimers repress transcription through class B E-box elements. Journal of Biological Chemistry $27746544-46551$.

Schreiber E, Matthias P, Muller MM \& Schaffner W 1989 Rapid detection of octamer binding proteins with mini-extracts prepared from a small number of cells. Nucleic Acids Research 176419.

Slominski A, Ermak G \& Mihm M 1996 ACTH receptor, CYP11A1, CYP17 and CYP21A2 genes are expressed in skin. Journal of Clinical Endocrinology and Metabolism 81 2746-2749.

Sugarawa T, Kiriakidou M, McAllister JM, Kallen CB \& Strauss JF 1997 Multiple steroidogenic factor 1 binding elements in the human steroidogenic acute regulatory protein gene $5^{\prime}$-flanking region are required for maximal promoter activity and cyclic AMP responsiveness. Biochemistry 36 7249-7255.

Tremblay JJ \& Viger RS 1999 Transcription factor GATA-4 enhances Müllerian inhibiting substance gene transcription through a direct interaction with the nuclear receptor SF-1. Molecular Endocrinology 13 1388-1402.

Zhang P \& Mellon SH 1996 The orphan nuclear receptor steroidogenic factor-1 regulates the cyclic adenosine 3',5'-monophosphate-mediated transcriptional activation of rat cytochrome P450c17 (17 $\alpha$-hydroxylase/c17-20 lyase). Molecular Endocrinology 10 147-158.

Received 19 January 2004 Accepted 4 February 2004 